\title{
ERRATUM
}

\section{Making Visible the First Women in Astronomy in Australia: The Measurers and Computers Employed for the Astrographic Catalogue - ERRATUM}

\section{Stevenson, $\mathrm{T}$.}

doi:10.1017/pasa.2014.12, Published by Cambridge University Press, 1 April, 2014.

In the original publication of "Making Visible the First Women in Astronomy in Australia: The Measurers and Computers Employed for the Astrographic Catalogue" by T. Stevenson, an error was introduced regarding Figures 3 and 4 . The image currently labeled as Figure 3 should instead be Figure 4. The image currently labeled as Figure 4 should instead be Figure 3. The author regrets this error.

\section{Reference}

Stevenson, T. (2014) Making Visible the First Women in Astronomy in Australia: The Measurers and Computers Employed for the Astrographic Catalogue. Publications of the Astronomical Society of Australia, 31. 